In the first place vaginal douching with any drug whatsoever is bad treatment for purulent vaginitis, simply because the solution cannot come in contact with the whole of the diseased surface; and if the patient douches herself, only the lower half of the vagina is douched. The best treatment is the wool tampon method; pledgets of wool, soaked in the drug it is wished to apply, are packed in the vagina through a Ferguson's speculum, and changed every aay. Cases treated in this way do well if the disease has not spread to the uterine cavity.

With regard to the drugs best to use, Dr. Giles only mentions lysol and chinosol among the "new-comers." These are fairly good, but others are much better. The best in my experience, and, curiously enough, one that has not yet been advertised as a certain cure for gonorrhoea, is maphthol.

I am, Sirs, yours faithfully,

London Look Hospital, May 17th, 1897.

murexide reaction. Mr. Shearer has wrongly appreciated the extraction process employed by me when he refers to it as "a process in which the error of estimation is from one to two milligrammes." What I stated in my Goulstonian Lectures was that when I added known quantities of uric acid to blood I could only extract from 80 to 87 per cent. of it, so that if a given bulk of blood contained one milligramme of uric acid, the process would enable four-fifths of that milligramme to be extracted. Permit me to remind Mr. Shearer that if the uric acid contained in the urinary excretion is derived from the blood, the blood of birds should contain an abundant quantity of it, since their urinary excretion consists entirely of a compound of uric acid. As Sir Alfred Garrod originally showed, no uric acid is present in the blood of birds, an observation which was confirmed by my experiments, in which pints of birds' blood were operated upon at a time.

I am, Sirs, yours very truly,

Weymouth-street, W., May 19th, 1897. ARTHUR P. LUFF.

\section{THE CENTRAL LONDON OPHTHALMIC HOSPITAL AND THE REPORT OF THE HOSPITAL REFORM ASSOCIA'ITON.}

\section{To the Editors of THE LANCET.}

SIRS, - I am requested by my committee to ask you to Bindly allow me space to correct the mis-statements in the above report as regards the Central London Ophthalmic Hospital. The tabular statement states :-

Subscribtrs' letters.- "Oat-patients : Yes, about half. Insatients: Yes."-No subscribers' letters are required, and less than 2 per cent. of the out-patients come with them. The same remark applies to the in-patients, as they are admitted from the out-patients.

Payment by patients.-- "Out-patients : $2 d$. a visit to $2 s$. $6 d$. per month; $£ 426$ a year. In-patients : all expected to pay $1 s$. a day ; occasionally, $£ 1$ a week ; $£ 30$ a year."-No charge is compulsory to out-patients, but some pay $2 d$. a visit, some $2 s .6 d$. a month in aid of the funds of the hospital. In the way in-patients are admitted free, but such as are able are expected to pay $1 s$. a day for their maintenance. As a matter of fact, the payment is very exceptional. Since the abolition of a private ward in 1890 no in-patient has paid more than 7 s. per week.

Inquiry officer.- "Inquiry officer fills in forms, \&x., and if he thinks proper brings the patients up to the secretary to be inquired into; has no power himself to question." "Inquiry efficer only in name."-There is a proper inquiry officer, appointed in 1894, who is empowered to question patients as to their means, and who rejects those whose position does not entitle them to hospital relief.

I am, Sirs, yours faithfully,

JoHN GRIGGs BryANT, Secretary.

Gray's-inn-road, May 17th, 1897.

\section{"THE SUCCESSFUL TREATMENT OF A WOUND OF THE HEART."}

\section{To the Editors of THE LANCET.}

SiRs,-In your Berlin Correspondent's notice of the German Surgical Association a very interesting notice of Dr. Rehn's case of wound of the heart and of his opening the pericardium is given, and without in the least wishing to detract from the credit justly due to Dr. Rehn for his bold and sound surgery I write to remind your younger readers that the opening of the pericardium, the removal of foreign bodies from it, and the washing of the sac was practised and taught by John Bell-that great surgeon who anticipated so many of our modern surgical methods.

Dublin, May 11th, 1897. I am, Sirs, yours traly, George Foy.

\section{URIC ACID IN THE BLOOD.}

\section{To the Editors of THE LANOET.}

SIRS,--With reference to the statement of Mr. D. F. Shearer in THE LANCET of May 15th that my experiments do not appear to justify the statement that blood contains no uric acid, it is evident that Mr. Shearer does not quite appreciate the extreme delicacy of the murexide test for uric acid. Not only can half a milligramme of uric acid be detected with ease by that test, but I find that the onebundredth part of a milligramme gives a very evident

\section{"POST-PARTUM HÆMORRHAGE AND ITS TREATMENT." \\ To the Editors of THE LANCET.}

SIRS, - In his letter in THE LANCET of Jan. 16th last under the abore heading Mr. E. Suanmore Bishop amongst other things indicates that he does not clearly comprehend my method of treatment as described in THE LANCET of Dec. 19th, 1896, and asserts that I speak with some doubt, stc, as to the efficacy of the procedure. I would crave of you a little space to make clear what may seem ambiguous, to show that there was little doubt in my mind, and also to make a few remarks on the position Mr. Bishop has taken up. I would state that when I wrote no one was more ready to rejoice with Mr. Bishop on his being able to point to some method of a definite nature to be pursued on being called upon to render help when a person's life is at stake-a means of freedom from, and a getting rid of, the confusion of the text-books, for I must say that with Mr. Bishop's beautiful description of the state of affairs found therein I am in the most perfect accord; but I wrote with a profound conviction that however effective in preventing the blood flow compression of the aorta may be, he was placing it entirely in the wrong position. I hope Mr. Bishop will be kind enough not to think that I wished to press his analogy too severely, and I really do not consider that I did so. I might have gone on and pointed out that in dealing with post-partum hæmorrhage we are assisting at a physiological function, but in dealing with a cut leg it is a different thing, \&c., but that might have seemed unkind, and, as I thought, unnecessary. This reminds me that the simile of the plumber is also, I am sorry to say, a very unhappy one, for if a pipe is spouting and injuring valuable property a plumber is called and simply covers the aperture with his thumb instead of putty; I am inclined to think we would not consider him the kind of gentleman Mr. Bishop indicates. Now, in regard to the closing of the bloodvessels with one hand inside and the other one outside let me hasten to assure Mr. Bishop that his assumption that I meant what I said is quite correct. I meant it in all seriousness. The difficulty of compressing the two arteries and accompanying veins with the thumb need not be any annoyance to anyone, for on being reminded that uteri vary in size and condition and that men's hands are not equal in magnitude and power of grasp, and that it cannot be called a step from this to pressing one set of ressels against the pelvic wall and setting the left hand free to close the vessels of the other side-I say, on being reminded of this, we may safely assume that a moment's reflection on the great law of adaptability will settle the whole matter.

Let us look now at compression of the aorta as put forward by Mr. Bishop. As already stated, I hold he has placed it entirely in the wrong position; its fatal feature is that it does not meet the great requirement-a good working method. Let me quote his words: "From first to last, however, in every case, whether complicated by retained placental fragments, torn cervix, or any other condition, the one and only measure of primary importance in the treatment of post-partum hæmorrhage is compression of the aorta." This is a sweeping statement and requires a deal of reading. Let us see where it leads us, and let us suppose that there is 
no objection to the process, such as may arise from pressure on the nerves, shutting off the blood-supply to important structures, the danger of not being able to compress the aorta above the origin of the ovarian arteries, especially when abnormally high at their origin, the difficulty, as your correspondent " Rinaldo" very properly points out, of extreme obesity, the danger of shutting the vena cava, the danger of closing the left renal vein, and that even the danger of regurgitation is absent-let us suppose these objections are all removed, and see what happens. Called to a case of bleeding, we are first of all to close the aorta, and keep it closed till the womb contracts and shuts the bloodvessels, and this too whether there are pieces of placenta present or not. Indeed, we are not to stop to find what is the cause of the bleeding. If it should be a piece of placenta, then I suppose it is to remain there, and our duty is to hold fast by the aorta. The womb is to be left to take care of itself and expel the placental fragments, clots, $\& c$. , or retain them, as the case may be-it is to fight out its own battle and strive against the difficulties nature has put in its way, and to do this in spite of the disadvantage we put it to by cutting off the blood-supply, and may I ask if it is to follow that we may then claim the gratitude of the patient for having saved her life? I would not that I should be understood to say that the aorta cannot be closed effectually, nor, indeed, should I say that it would not be a valuable method for staying post-partum hæmorrhage if a better were not at hand; but I do say that to put it forward as the first thing to be done in all cases is utterly and entirely wrong, and were this practice to be generally adopted it would lead us into following the most ridiculous and foolish procedure. I is difficult to conceive of a case where we need resort to this roundabout and rather clumsy practice - a practice which, as is shown above, requires two skilled persons to be present. Really the only case one can conceive of where this plan can claim any advantage is when there is no disinfecting material at command, and thus the only case where it may be useful is when we have unwashed hands, and even here there remains much room to doubt whether it is not inferior to the intelligent application of external pressure on the uterine surface directed so as to compress the arteries and veins as formerly described.

Regarding the important question of regurgitation I would like to say a few words, but I feel it may appear too great a presumption on $\mathrm{my}$ part, for if Mr. Bishop gives such short shrift to the opinions of men whose names we all revere what is likely to befall mine? However, if he will kindly accompany me for a little I will make bold enough to undertake to show that it is quite possible that these authorities may be right after all. When labour has been completed and the muscular tissue of the womb entirely fails to contract we have a condition in which there are four patent passages from the vena cava to the bleeding uterine surface except in those cases where there are valves in the ovarian veins. Should those veins be valved there remain the two uterine veins, Thus we have always at least two open channels. Now physiology tells us that the negative endocardial pressure or sucking power of the right auricle assisted by the respiratory act is about $-12 \mathrm{~mm}$. to $-7 \mathrm{~mm}$ of mercury in ordinary health, and let $\mathrm{ns}$ suppose that this is reduced by weakness and loss of blood to say $-3 \mathrm{~mm}$. or $-4 \mathrm{~mm}$ - a little less than half. This is equal to about 0.118 inch of mercury in the first case and 0.157 inch in the latter. And if mercury be about thirteen times as heavy as blood, it means that the uterine surface requires to be from $1 \frac{1}{2}$ to 2 inches lower than the auricle to establish equilibrium, or in other words that the auricle, even with the help of the inspiratory suction power, is just able to prevent the blood flowing backwards towards the womb by the action of gravity; and it must be noted too that we have to grant that those flaccid and extremely feeble venous structures are able to sustain this pressure. Here, then, we have a very delicately balanced apparatus, and what is to happen when the abdominal muscles or the limbs are put in action? What can happen but blood will flow towards the open ends of the tubes, and so also should there be a frequent cough? What is to occur but that there shall be four streams carrying blood from the vena cava into the womb upon every movement of the chest? and the same must be the case with retching, vomiting, sneezing, or pressure with the hand or otherwise on the abdominal wall; each of these things must upset the equilibrium, and I should add upset it very completely too. We cannot make any pretence of assisting the heart to any appreciable degree by taking advantage of the force of gravity, for it must be borne in mind that when we raise the foot of the bed we only raise the part where the pelvis is situated by about one-half the distance which we raise the foot, and the part with which the auricle corresponds also partakes of the rise, though to a less degree; thus the assistance is extremely little, and cannot be for a moment placed in opposition to the force brought o bear on the vessels by the movement of a limb, and much less the pressure produced by a cough.

In conclusion, I would express a hope that $\mathrm{Mr}$. Bishop will see his way to fall into line with me, and lend his valuable help in elucidating and making known a method suited to meet all cases, from the most trivial to the most severe, which is hardly a step removed from the routine practice of every practitioner, which comes natural to us and which we might almost call the natural method, which is immediate in its application, causes little or no pain or discomfort, and which, to put it shortly, is a good working method. I am, Sirs, yours truly,

Heywood, Lancashire. Thomas Laine.

\section{To the Editors of THE LANCET.}

SIRS,-As a reader of your most valuable journal I have been great]y interested in the controversy on the above subject, which was some time ago carried on in THE LANCET between Mr. Stanmore Bishop of Manchester and Dr. T. Laird of Heywood. Now that such a lenghtened interval has elapsed since your last published communication on the subject appeared $I$ begin to fear the controversy has been concluded, and in so assuming I feel a keen sense of disappointment at what appears to $\mathrm{my}$ mind to be a premature closing of a correspondence on a matter of so high import. ance to all general practitioners. As one who has had an extremely limited experience among patients suffering from post-partum hæmorrhage, having been brought into contact with some three or four cases only, I feel it would be an act of great presumption to introduce myself into the arena of this debate. Still, doubtless along with many other interested young medical men, I should like to see this important question thrashed out a little more completely than it has been up to this stage, and I am yet loath to believe that Dr. Laird has said his last word on the subject ; for althoug in his last communication Mr. Stanmore Bishop defended his own position most vigorously, his defence, even in my humble judgment, is not impregnable, nor does it bear the stamp of finality as regards the question at issue.

There is a method of arresting post-partum hæmorrhage described in the work of Dr. King, Professor of Obstretrics in the Columbian University, Washington, which has recently attracted my attention, upon the merits of which I should much esteem an expression of opinion from either of the gentlemen above named. I give the author's own words:-"A special mode of grasping the uterus-bi-manual manipulation-may be tried as follows: Press the finger ends of the outside hand deep in between the umbilicus and the uterus, so that the latter resting in the palm may be pushed down and forward against the pubes, while the other hand (or two fingers of it), passed high up along the posteria vaginal wall, presses the lower segment of the womb-in fact, its cervix-forward towards the symphysis pubis; thus by a sort of temporary anteflexion the canal of the neck is closed and no blood can come out, while the pressure above prevents enlargement of cavity and accumulation within. It also stimulates contractions."

The foregoing method has commended itself to me all the more fascinatingly since a conversation I had on this subject a few weeks ago with a very intimate medical friend, whose obstetric experience covers over 3000 cases of labour, including fully twenty cases in which serious after-bleeding was exhibited, who stated to me that the method just described is the one he always adopts, and that he has never yet lost a case from this complication. From a theoretical point of view most of the disadvantages cited against aortic compression could not be adduced in connexion with the plan just given, whilst on the ground of the latter's practicability and efficiency the experience I have quotec greatly enhances, I think, its inherent value.

I am, Sirs, yours faithfully,

JosePh M. ThoRNLEY, M.B., C.M. Glasg.

Bolton, Lancashire, May 10th, 1897. 